Review

\title{
Clinical Utility of Preoperative Assessment in Ovarian Cancer Cytoreduction
}

\author{
Pratistha Koirala *, Ashley S Moon and Linus Chuang \\ Department of Obstetrics and Gynecology, Division of Gynecologic Oncology, Danbury Hospital, \\ Danbury, CT 06810, USA; ashmoon@stanford.edu (A.S.M.); linus.chuang@wchn.org (L.C.) \\ * Correspondence: pratistha.koirala@wchn.org
}

Received: 15 July 2020; Accepted: 2 August 2020; Published: 7 August 2020

\begin{abstract}
Ovarian cancer is the deadliest gynecologic cancer, in part due to late presentation. Many women have vague early symptoms and present with disseminated disease. Cytoreductive surgery can be extensive, involving multiple organ systems. Novel therapies and recent clinical trials have provided evidence that, compared to primary cytoreduction, neoadjuvant chemotherapy has equivalent survival outcomes with less morbidity. There is increasing need for validated tools and mechanisms for clinicians to determine the optimal management of ovarian cancer patients.
\end{abstract}

Keywords: ovarian cancer cytoreduction; neoadjuvant chemotherapy; preoperative predictors of optimal tumor cytoreduction

\section{Introduction}

Although ovarian cancer represents only $1.3 \%$ of newly diagnosed cancers in the United States, it accounts for $2.3 \%$ of overall cancer related deaths [1]. In women, ovarian cancer is the second most common but deadliest gynecologic cancer, and the fourth deadliest overall cancer [2]. Approximately $80-90 \%$ of ovarian cancers occur in women between the ages of 20 - and 65 -years-old, and $60 \%$ of ovarian tumors are of epithelial origin [3]. Currently, the five-year-survival rate for ovarian cancer is less than $50 \%$. Prophylactic salpingectomy can be performed opportunistically at the time of other surgeries, such as cesarean section or during non-gynecologic procedures, and has been shown to reduce ovarian cancer risk [4]. Due to a lack of effective screening methods and vague symptoms, ovarian cancer often presents at later, disseminated stages, leading to higher mortality compared to less prevalent cancers. With the exception of high risk women with known hereditary cancer gene mutations, the United States Preventive Services Task Force recommends against ovarian cancer screening in asymptomatic women as current methods have high false positive rates which can lead to unnecessary surgical interventions [5]. Due to the inability to detect ovarian cancer at early stages, over two-thirds of newly diagnosed cases present at stage III and IV [6].

Historically, ovarian cancer presenting at any stage was managed with primary cytoreductive surgery followed by adjuvant chemotherapy. Recent literature has demonstrated that advanced stage cancers have improved surgical and equivalent survival outcomes with neoadjuvant chemotherapy. Within the last few years, poly ADP ribose polymerase (PARP) inhibitors have demonstrated improved survival and reduced risk of recurrent disease in newly diagnosed advanced ovarian, fallopian tube and peritoneal cancer after response to first-line platinum neoadjuvant chemotherapy in homologous recombinant deficiency populations [7]. This was based on prior trials that showed PARP inhibitors increased progression-free survival in platinum-sensitive recurrent ovarian cancer in both breast cancer gene (BRCA) mutated and non-BRCA mutated patients [8]. These changes in management necessitate clinicians to utilize tools to stratify patients to the most appropriate management. 


\section{The Role of Neoadjuvant Therapy versus Primary Cytoreduction}

Until the recent advancement of PARP inhibitors, the pillars of ovarian cancer treatment have been cytoreductive surgery and chemotherapy. Both techniques are utilized, but the sequence with which they are used is dependent on stage and presentation. In cases where optimal cytoreduction can be achieved, the preferred treatment method is primary surgery followed by a platinum-based chemotherapy regimen $[9,10]$.

The Gynecologic Oncology Group (GOG) has previously defined optimal tumor cytoreduction as less than $1 \mathrm{~cm}$ of residual disease [11]. There is evidence that minimizing residual tumor to any degree improves survival outcomes, with one study demonstrating median survival ranging from 48 to 66 months depending on the degree of residual tumor (less than $1 \mathrm{~cm}$ remaining versus median survival of 106 months in patients with no residual disease after primary cytoreduction [12]). There is evidence that less than $1 \mathrm{~cm}$ of residual disease has efficacy, but the current goal of cytoreductive surgery is to achieve complete tumor resection with no evidence of remaining disease [11,13].

If there is concern that optimal cytoreduction cannot be achieved, patient outcomes are improved by administering neoadjuvant chemotherapy followed by interval tumor cytoreduction. In the last decade, this paradigm shift towards neoadjuvant treatment prior to cytoreductive surgery has maintained survival outcomes with less surgical morbidity.

The 2010 European Organization for Research and Treatment of Cancer (EORTC) trial was the first major study to address the outcomes between primary cytoreduction versus neoadjuvant chemotherapy. In this study, 632 patients with either stage IIIC or IV ovarian, fallopian tube, or primary peritoneal carcinoma were randomly assigned to either undergo platinum-based neoadjuvant chemotherapy, followed by interval or primary cytoreductive surgery, followed by adjuvant platinum-based chemotherapy. For patients undergoing neoadjuvant chemotherapy, the hazard ratio was 0.98 for death and 1.01 for progressive disease, showing that this treatment was non-inferior to the standard of care at that time. Postoperative complications and mortalities were higher after primary cytoreduction [14].

The 2015 primary chemotherapy versus primary surgery for newly diagnosed advanced ovarian cancer (CHORUS) trial performed similar randomization of 550 patients with stage III or IV ovarian cancer. Their findings replicated those of the EORTC trial, with a hazard ratio of 0.87 favoring primary chemotherapy in their patient population [15]. A 2016 Japan Oncology Group Study confirmed these findings in a randomized control trial of 301 patients. Not only did they find neoadjuvant chemotherapy non-inferior, they also noted that these patients ultimately underwent less invasive surgical procedures and suggested that this may be a new standard of care [16].

A 2016 superiority trial, primary surgery versus neoadjuvant chemotherapy in advanced epithelial ovarian cancer with high tumor load (SCORPION trial), randomized 110 women with ovarian cancer to either undergo primary cytoreduction or neoadjuvant chemotherapy. In this trial, rather than using stage to qualify a cancer as 'advanced', all participants underwent diagnostic laparoscopy to determine tumor burden and the extent of their disease. This trial demonstrated that not only was neoadjuvant chemotherapy superior in mortality outcomes, but that it was associated with improved quality of life metrics compared to primary cytoreductive surgery [17].

Ultimately, complete surgical resection of ovarian cancer remains the standard of care, but there are multiple approaches to achieving this goal. The ability to achieve this goal is multifactorial, ranging from the properties of each individual tumor to the ability of the surgeon performing cytoreduction. Many early stage ovarian cancers can be managed with primary cytoreduction with the addition of adjuvant chemotherapy, whereas stage IV ovarian cancers have a variable chance of optimal primary cytoreduction (ranging from $15 \%$ to $85 \%$ [18,19]). Poor functional and nutritional status may deem a patient an unsatisfactory candidate for primary cytoreduction. In these cases, neoadjuvant therapy can be started and the patient is reassessed (often at the midpoint of a six-cycle regimen). If appropriate, interval cytoreduction can be performed at that time.

The branch point in determining if a patient is a candidate for primary versus interval cytoreductive surgery is ill-defined. There are currently no high-fidelity models to predict success rates in achieving 
optimal cytoreduction, leading to suboptimal cytoreduction and large residual disease burden in some patients. In the aforementioned studies, the included eligible patients were those with biopsy-proven stage IIIC or IV primary ovarian, peritoneal, or fallopian-tube carcinoma, the presence of a pelvic mass, the presence of at least a $2 \mathrm{~cm}$ metastasis outside the pelvis, or regional lymph node metastasis. A ratio of serum cancer antigen-125 (CA-125) to carcinoembryonic antigen (CEA) of 25 or higher was required along with other negative metastatic evaluations including mammography and gastroenterology studies. Patients had to have a World Health Organization performance status of 0 (asymptomatic) to 2 (symptomatic) and have no serious disabling diseases that precluded them from undergoing cytoreductive surgeries [14-17].

Efforts have been made to standardize preoperative assessment in determining surgical versus medical management. Nomograms have been developed to predict disease-specific survival for advanced ovarian cancer patients who underwent cytoreductive surgery and adjuvant platinum-based therapy [20-22]. Prognostic factors were studied such as age, performance status, tumor histology, residual disease. External validation studies of these predictive models have been performed, which showed adequate applicability, but concluded that missing data and a wide range of variables diminished their clinical utility [23]. In this review, we discuss some of these clinical predictors, including tumor and molecular markers, preoperative imaging, functional status, and diagnostic laparoscopy. We further comment on clinical decision making and management in resource limited settings.

\section{Functional Status}

Nearly half of ovarian cancer patients are over the age of 64 and $25 \%$ are over the age of 74 [1]. Many patients present at late stages with multiorgan involvement and manifestations such as ascites. In addition to disease related impairments on functional status, many older patients have comorbid conditions. Regardless of comorbidities, age is an independent prognostic factor, with patients over 80 having significantly higher perioperative mortality and morbidity, including kidney failure, pulmonary, and cardiovascular compromise [24,25]. Perioperative complication rates increase with each age group and are further compounded by tumor burden [26]. In another study, although age was not found to be prognostic, older patients consistently had worse outcomes despite intention to treat [27]. Due to the association of increasing age with poorer outcomes, we recommend to consider a pre-operative functional and nutritional status analysis in patients over 65 years of age.

Multiple studies found that low serum albumin levels, a stand in for poor nutritional status, were negatively associated with survival and that this association was durable across all stages of ovarian cancer and other history $[25,26,28]$. In one study, subgroup analysis demonstrated significantly poorer survival in laparotomy but not laparoscopic cases. Hypoalbuminemia is associated with increased resource utilization, such as longer hospital and intensive care unit length of stay [29]. In gastrointestinal surgeries, hypoalbuminemia was associated with increased rates of surgical site infections. Serum albumin levels provide a noninvasive method to assess the risk associated with surgical intervention [30]. Specifically, a preoperative albumin of less than $3.5 \mathrm{~g} / \mathrm{dL}$ has been associated with poor survival outcomes in multiple studies [28-30]. A meta-analysis by Ge et al. found that $0.1 \mathrm{~g} / \mathrm{dL}$ increases in serum albumin levels were significantly associated with improved survival outcomes [31]. Patient with severe hypoalbuminemia should be considered for nutritional support for one to two weeks to optimize surgical outcomes [32,33].

Elderly patients often receive less aggressive treatment. In one study, elderly patients with poor nutritional status and extensive tumor burden had increasing morbidity with no added survival benefit [34]. Patients often also have delays in the initiation of adjuvant chemotherapy or reductions in dosage due to complications of cytoreductive surgery. These delays are more likely to occur in elderly patients and are associated with significantly worse overall survival [35]. Despite potentially worse outcomes in elderly patients, surgical intervention should still be considered for otherwise appropriate candidates being managed in high volume centers with multidisciplinary care teams $[27,36]$. In addition to age and nutritional status, as measured by serum albumin levels, a patient's cardiopulmonary function and status can be evaluated using the American Society of Anesthesiologists Physical Classification System 
(ASA score) which accounts for comorbid conditions [37]. Patients with higher ASA scores tend to have worse postsurgical outcomes [24,38]. These parameters can play a role in creating individualized treatment plans and care should be taken to optimize nutritional and functional status prior to cytoreductive surgery or chemotherapy.

\section{Tumor Markers}

Tumor and molecular markers are widely used and serve a wide range of functions in cancer screening, detection and diagnosis, treatment planning, and disease monitoring. Screening tests must have high sensitivity and remain cost effective for maximal impact while diagnostic tests must have high specificity [39]. Currently, ovarian cancer tumor markers play a role in post-treatment disease monitoring but have a limited role in screening or diagnosis due to their lack of specificity. CA-125 is the most studied tumor marker for ovarian cancer. However, CA-125 can be elevated in non-gynecologic disease processes such as hepatitis, and in benign gynecologic conditions including normal menses [40]. Up to $50 \%$ of ovarian cancer cases can have normal CA-125 levels. Despite its limitations, CA-125 is currently the standard biomarker in ovarian cancer management and is used to monitor recurrence and disease response to treatment [41,42].

Three major studies have been performed over the past two decades to analyze the utility of CA-125 in combination with transvaginal ultrasound: as part of the Prostate, Lung, Colorectal, and Ovarian (PLCO) Cancer Screening Randomized Control Trial, the UK Collaborative Trial of Ovarian Cancer Screening (UKCTOCS), and the Shizuoka Cohort Study of Ovarian Cancer Screening (SCSOCS) trial $[41,43,44]$. The PLCO and SCSOCS trials demonstrated no significant difference in ovarian cancer mortality between women who had screening and those who did not $[41,45]$. Conversely, screening of asymptomatic women led to increased rates of surgical interventions and serious complications [45]. On the other hand, in a post-hoc analysis, the UKCTOCS showed long term decreased ovarian cancer mortality when using CA-125 in conjunction with the Risk of Ovarian Cancer Algorithm (ROCA) [46]. Due to the cost effectiveness of screening and a lack of clear evidence-based guidelines in the United States, CA-125 is not commonly used as a screening tool [47-49].

CA-125 may play a role in guiding primary cytoreduction versus neoadjuvant chemotherapy. In a retrospective study, Chi et al. found that preoperative serum CA-125 was correlated with successful optimal cytoreduction. The authors found that a preoperative CA- 125 cut-off of $500 \mathrm{U} / \mathrm{mL}$ was highly predictive of optimal cytoreduction, with values over the threshold resulting in suboptimal cytoreduction $80 \%$ of the time [50]. A second study evaluated this cut-off in their patients and reported a lower predictive value for a CA- 125 of $500 \mathrm{U} / \mathrm{mL}$, but noted that no patients with a CA-125 over $1500 \mathrm{U} / \mathrm{mL}$ had optimal cytoreduction [51]. The authors suggested utilizing diagnostic laparoscopy to make a final decision for patients who had a CA-125 value greater than their cut-off of $500 \mathrm{U} / \mathrm{mL}$ [50].

Recent data have suggested that CA-125 and human epididymis protein 4 (HE4) can be used to stratify treatment algorithms. HE4 was identified as a gene of interest in ovarian cancer and has shown promise in differentiating benign versus malignant ovarian lesions. Similar to CA-125, HE4 levels fluctuate in relation to disease burden [52]. When multiple markers were studied, including CA-125, only HE4 had prognostic value immediately after surgical cytoreduction [53]. Other studies have shown that a combination of HE4 and CA-125 may have a higher diagnostic utility and surgical outcome predictability than either marker alone [54,55]. Cutoff values of preoperative serum HE4 and CA-125 of $777.10 \mathrm{pmol} / \mathrm{L}$ and $313.60 \mathrm{U} / \mathrm{mL}$, respectively, were suggested by the authors to accurately predict outcomes of cytoreductive surgeries [55]. A study by Chudecka-Głaz found that HE4 may be an independent prognostic factor of chemotherapeutic treatment response. In this study, the normalization of HE4 after therapy or a 50\% reduction of HE4 levels before interval surgery was associated with a significant improvement in both progression-free and overall survival [56]. Although these studies are promising, the results are still preliminary, based on retrospective studies, and sample sizes were small. Larger studies are needed for tumor markers to play a standard role in the stratification of surgical and medical management. 


\section{Preoperative Imaging}

Transvaginal ultrasound (TVUS) is the mainstay in evaluating adnexal masses and is often the modality of choice given its clinical utility and cost effectiveness. TVUS is both sensitive and specific in the initial differentiation of benign versus malignant masses; when combined with color flow doppler, pattern recognition, and clinical background, TVUS reaches a sensitivity of $85 \%$ and a specificity of $90 \%[57,58]$. In some institutions, such as referral centers with expert operators, ultrasound has displaced computed tomography (CT) in the pre-operative evaluation of pelvic and abdominal masses [59]. Ultrasound alone has not been used to predict successful cytoreduction although it has been used as part of larger predictive models such as ROCA, which combines serum biomarkers and TVUS. Compared to ROCA, ultrasound alone has decreased positive predictive value [60]. A study is currently underway to further characterize the role of transvaginal ultrasound in predicting successful cytoreduction in ovarian cancer [61].

$\mathrm{CT}$ is an important tool in ovarian cancer diagnosis and staging. Its primary role is determining the extent of disease. On the other hand, the National Comprehensive Cancer Network and Society for Gynecologic Oncology guidelines recommend CT scans only when clinically indicated [62,63]. Choosing Wisely ${ }^{\circledR}$, a campaign on best practices from the American Board of Internal Medicine and the National Physician Alliance, advises against its routine use for surveillance [64]. Esselen et al. found that despite these guidelines, CT is commonly used in ovarian cancer surveillance even in the absence of clinical indications [65].

Multiple studies have attempted to validate $\mathrm{CT}$ as a predictor for successful primary surgical cytoreduction, with conflicting results. Some studies have suggested that CT may be a valuable predictor and specific findings, including mesenteric involvement and high grade ascites, may decrease the success of surgical cytoreduction [66-69]. Conversely, other studies found that CT was not predictive, or that it was equivocal, and cautioned against utilizing CT due to limited data and the small sample sizes of previous works [70,71]. A meta-analysis of these studies found that $\mathrm{CT}$ alone is a poor predictor of optimal cytoreduction and should be used with caution [72].

CT may have more utility in conjunction with other screening tools. Bristow et al. described a Predictive Index Score based on multiple radiographic findings, CA-125 levels, and functional status [73]. Subsequent studies have found that a combination of preoperative platelet count, functional status, and diffuse peritoneal thickening or ascites on $\mathrm{CT}$ was associated with suboptimal cytoreduction, but noted that the results needed external validation [74,75]. Multiple small trials have also assessed the predictive value of positron emission tomography (PET). These early results suggest a potential role for $\mathrm{PET} / \mathrm{CT}$ in predicting optimal primary or secondary cytoreduction. Overall, CT continues to be widely used although evidence is contradictory and future large-scale studies are warranted.

Magnetic resonance imaging (MRI) is not commonly used in the management of ovarian cancer but it plays a role in characterizing difficult-to-assess adnexal masses. To date, there are limited data on the role that MRI can play in ovarian cancer management. One study used MRI to determine the Peritoneal Cancer Index (PCI), a scoring system based on sites of disease in the abdomen. This study found that MRI was useful in determining the PCI and that it may have a role in predicting successful cytoreduction, but this study was limited with only 25 participants [76]. A second study had similar findings in a slightly larger sample of 50 patients, but further research is needed prior to expanding the role of MRI in the diagnosis and management of ovarian cancer [77].

\section{Minimally Invasive Approaches and Diagnostic Laparoscopy}

Ovarian cancer cytoreduction surgery has traditionally been performed by laparotomy with total abdominal hysterectomy, bilateral salpingo-oophorectomy, omentectomy, peritoneal biopsies, pelvic and paraaortic lymph node biopsy versus lymphadenectomy, and resection of all visible disease, which can involve other organ systems such as the bowel, spleen, and liver. Multiple studies have demonstrated that minimally invasive techniques have value in evaluation, diagnosis, staging, and management of ovarian cancer [78]. To date, published studies have been retrospective analyses of small, carefully 
selected cohorts [79,80]. Both laparoscopic and robotic approaches have been utilized [81]. Despite this preliminary evidence, further research is needed on the role of minimally invasive cytoreductive surgery in ovarian cancer [82].

One strength of diagnostic laparoscopy is that initial evaluation can be performed, allowing the surgeon to directly visualize the tumor burden prior to making a decision on how to proceed. A 2005 study by Fagotti et al. sought to determine the accuracy of laparoscopic assessment in a randomized clinical trial of 95 patients, 64 of whom met the inclusion criteria. Patients who met the inclusion criteria underwent diagnostic laparoscopy, at which point the surgeon determined if the patient was a candidate for primary cytoreduction or if she were better suited for neoadjuvant chemotherapy. Regardless of the evaluation, all patients then underwent laparotomy and primary cytoreduction. In this powerful study, although some patients who were deemed appropriate for primary surgery had suboptimal cytoreduction, there were no patients who had been deemed unsuitable for cytoreductive surgery whose tumors were, in fact, optimally debulked [83]. Multiple studies have utilized the model proposed by Fagotti et al. and demonstrated its utility in their patient populations and for interval cytoreduction after neoadjuvant chemotherapy [84-86]. A Cochrane review of diagnostic laparoscopy suggests that it may have a role in the management of ovarian cancer, but the data are limited [87]. To date, these studies show that laparoscopy has the potential to avoid 'futile laparotomies' [88].

\section{Liquid Biopsy}

Liquid biopsies, most commonly acquired through blood samples, allow for tumor surveillance and have the potential to tailor treatment for precision medicine. Liquid biopsy utilizes circulating tumor cells (CTCs), circulating tumor DNA (ctDNA), circulating cell-free microRNAs, and circulating exosomes to diagnose and monitor cancer. CTCs are more commonly found in advanced stage (III and IV) than early stage ovarian cancer [89]. They are released from primary, metastatic or recurrent ovarian cancers and can be identified in the peripheral blood [90]. It is technically challenging to detect CTCs in whole blood as the ratio of CTCs to non-tumor cells is low. Immunocytochemistry or gene expression analysis such as real-time PCR (RT-PCR) allow for the enhanced detection of CTCs [91,92]. Potential biomarkers on CTCs have been uncovered using molecular profiling [93].

CTCs have been shown to be a predictor of treatment response [92]. Patients with platinum-resistant ovarian cancer have substantially higher CTCs when compared to those with platinum-sensitive tumors [94]. ctDNA may be more reliable that CTCs as a biomarker of response to treatment and long-term prognosis. TP53 mutant-ctDNA detection rates of $75 \%$ to $100 \%$ have been reported in patients with high grade serous ovarian cancer [94,95]. Persistence of TP53 gene variants in ctDNA after neoadjuvant chemotherapy correlated to the presence of minimal residual disease [96]. ctDNA in ovarian cancer has been shown to be more accurate than CA-125 and imaging to predict tumor responses [97].

MicroRNAs (miRNAs) are a class of noncoding RNA with a length of 20-25 nucleotides. As a result of the deregulation of miRNAs, changes in the target genes lead to ovarian cancer progression [98]. Plasma miRNA levels may serve as a diagnostic biomarker for ovarian cancer [98,99]. Exosomes are 30-150 nm-sized extracellular vesicles of endocytic origin which play key roles in cancer biology by mediating cell-to-cell communication through the transfer of proteins, nucleic acids, and lipids [100]. Exosome research has rapidly expanded over the last decade in ovarian cancer. Recent studies have demonstrated that exosomes promote peritoneal dissemination through an interaction between cancer cells and their microenvironments. Targeting exosomes may have potential as diagnostic and therapeutic biomarkers for ovarian cancer $[97,100]$. Liquid biopsy to detect tumor cells and monitor aberrant gene expression are promising in their ability to detect, diagnose, and monitor ovarian cancer. With further studies, they may also represent tools to triage and predict treatment response, such as neoadjuvant chemotherapy versus primary cytoreduction. 


\section{Considerations in Resource Limited Settings}

Gynecologic cancers are currently disproportionately represented in low resource settings with low and low/middle income countries (LIC and LMICs) expecting to see the largest growth in these malignancies [101]. There is evidence that patients with gynecologic malignancies have improved morbidity and mortality outcomes when treatment is driven by a trained gynecologic oncologist compared to a general obstetrician gynecologist or a surgical oncologist [102]. Many of these LIC and LMICs have variable or no training programs in gynecologic oncology and their ability to deliver care varies greatly, leading to global inequities in treatment $[103,104]$. Over the past decade, multiple initiatives have fostered the training of gynecologic oncologists globally with a focus on delivering surgical care [101].

In settings where both surgical and medical management are available, cost often limits the treatment choice. In Kenya where both modalities are available, chemotherapy is often unaffordable for many patients [105]. Multiple studies have evaluated the cost effectiveness of primary cytoreduction versus neoadjuvant chemotherapy. Three studies found that with the exception of high risk subgroups, such as patients older than 65 years, primary cytoreduction is more cost effective than neoadjuvant chemotherapy [106-108]. Although cost should not be the sole determinant of management, it will undoubtedly play a role in LIC and LMICs, where sometimes only surgical management is available. Conversely, at times of resource limitations and decreased surgical availability, even in higher income countries, neoadjuvant chemotherapy may become more prevalent. With a global pandemic and cancellation of non-urgent or emergent surgeries in most of the United States, it will be interesting to see the impact on management choices and long-term morbidity and mortality outcomes in these patients.

\section{Summary}

Improved surgical outcomes reported by the EORTC and the CHORUS trials have driven neoadjuvant chemotherapy as the initial treatment of choice for advanced stage ovarian cancers $[15,109]$. These trials demonstrated that neoadjuvant chemotherapy is non-inferior to primary cytoreduction for patients with stage IIIC and IV ovarian cancer. There has been controversy within the medical community on how to best apply these findings, with some groups arguing that all advanced ovarian cancer patients should undergo neoadjuvant chemotherapy while others maintain that primary cytoreduction has a role in well selected patients [9]. These factors were reviewed in this paper and their current utility in clinical decision making is summarized in Table 1. There have been multiple models that account for prognostic factors: functional status, tumor markers, imaging, and diagnostic laparoscopy in order to predict which patients are candidates for optimal cytoreduction. In Figure 1 we present a general algorithm for the evaluation and management of adnexal masses in a nonpregnant patient. Many of these trials are limited in their sample size, or have a wide range of variables, or unavailable data. Further studies, including genetic and molecular profiling, are needed to optimize a predictive model to help clinicians determine the best treatment course for their patients.

Table 1. Preoperative assessment. CT: computed tomography. MRI: magnetic resonance imaging.

\begin{tabular}{cc}
\hline Factors & Predictive Value \\
\hline Age $(\geq 65$ years old) & High \\
Functional status $(<4$ metabolic equivalents) & High \\
Nutritional status (weight loss $>5 \%$ premorbid weight) & High \\
Albumin level $(\leq 3.5 \mathrm{~g} / \mathrm{dL})$ & High \\
Tumor markers $(>500$ units $/ \mathrm{mL})$ & Moderate \\
CT scan (ascites, carcinomatosis) & Moderate \\
MRI (carcinomatosis and liver metastasis) & Low to moderate \\
Diagnostic laparoscopy (carcinomatosis and extensive mesenteric involvement) & Moderate to high \\
Genetic and molecular markers & In research \\
\hline
\end{tabular}




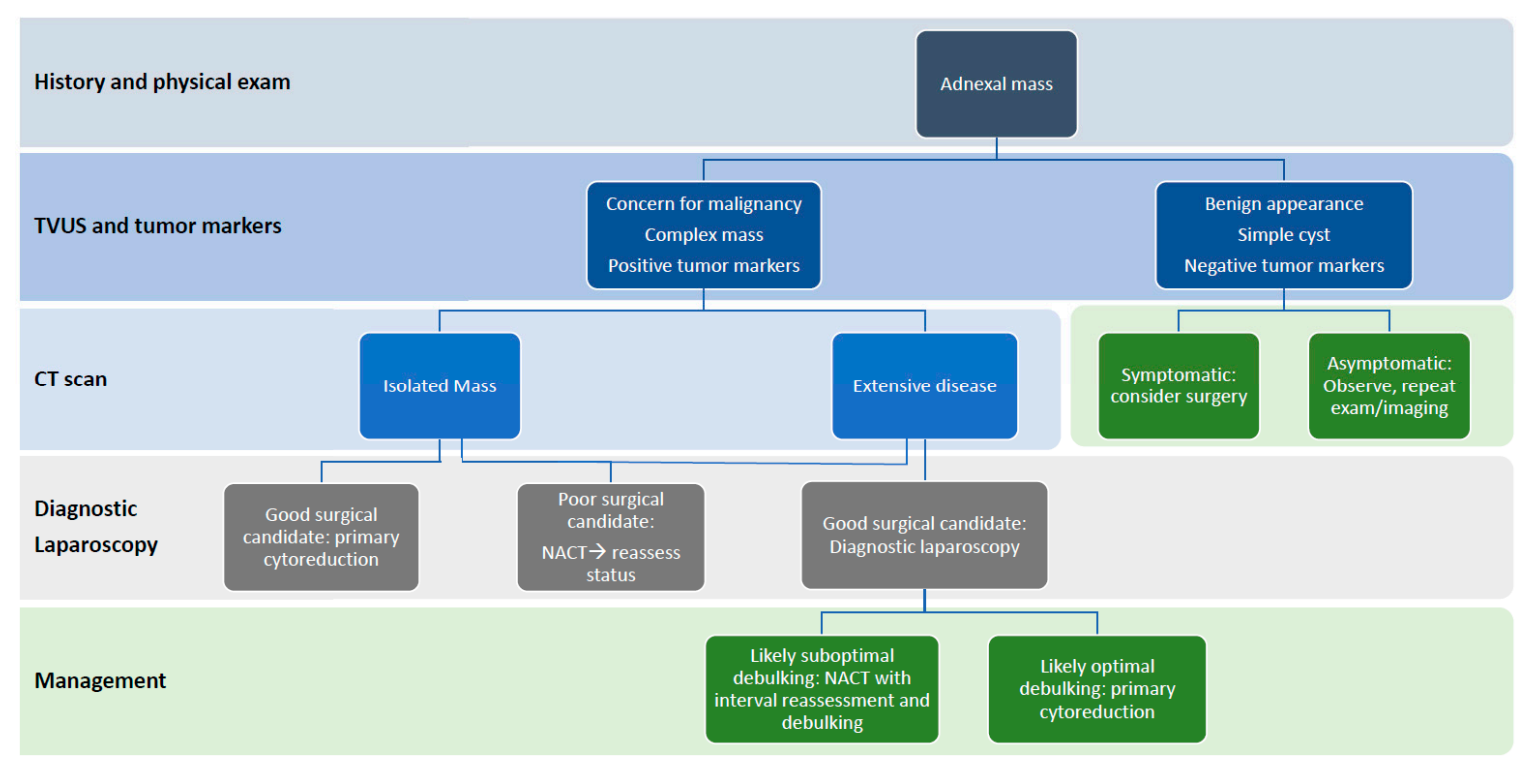

Figure 1. Preoperative assessment and management of an adnexal mass in a nonpregnant patient.

Evaluation of a patient with an adnexal mass should begin with a thorough history and physical exam. Once a suspicious mass has been identified, initial imaging with transvaginal ultrasound (TVUS) in conjunction with tumor markers is a powerful tool to differentiate likely benign from suspected malignant conditions, while a CT scan can assess for metastasis and extent of disease. In patients with an isolated mass, surgical intervention is warranted both for management and to provide tissue diagnosis. For patients with extensive disease on preoperative imaging, diagnostic laparoscopy allows the surgeon to assess the tumor under direct visualization and determine respectability. In cases of both an isolated or extensive tumor, functional status should be taken into account. All patients over the age of 65 years should undergo thorough nutritional and functional status screening to determine if they are good surgical candidates. Patients with serum albumin levels of less than $3.5 \mathrm{~g} / \mathrm{dL}$ should be offered preoperative nutritional support to optimize surgical outcomes. For all patients, co-morbid conditions and cardiopulmonary status should be determined using a scale such as the American Society of Anesthesiologists Physical Classification System. Primary cytoreduction should be offered for patients who are good surgical candidates and whose tumor can be debulked with no visible tumor remaining. Neoadjuvant chemotherapy should be offered to patients who do not meet these criteria with interval reassessment for surgical candidacy.

Author Contributions: P.K., A.S.M., and L.C. contributed to the writing of this manuscript. All authors have read and agreed to the published version of the manuscript.

Funding: This research received no external funding.

Conflicts of Interest: The authors have no conflict of interest to disclose.

\section{References}

1. Ovarian Cancer - Cancer Stat Facts. Available online: https://seer.cancer.gov/statfacts/html/ovary.html (accessed on 18 December 2019).

2. USCS Data Visualizations-CDC. Available online: https://gis.cdc.gov/Cancer/USCS/DataViz.html (accessed on 18 December 2019).

3. Devouassoux-Shisheboran, M.; Genestie, C. Pathobiology of Ovarian Carcinomas. Chin. J. Cancer 2015, 34, 50-55. [CrossRef] [PubMed]

4. Opportunistic Salpingectomy as a Strategy for Epithelial Ovarian Cancer Prevention | ACOG. Available online: https://www.acog.org/clinical/clinical-guidance/committee-opinion/articles/2019/04/opportunistic -salpingectomy-as-a-strategy-for-epithelial-ovarian-cancer-prevention (accessed on 2 May 2020). 
5. Grossman, D.C.; Curry, S.J.; Owens, D.K.; Barry, M.J.; Davidson, K.W.; Doubeni, C.A.; Epling, J.W.; Kemper, A.R.; Krist, A.H.; Kurth, A.E.; et al. Screening for Ovarian Cancer US Preventive Services Task Force Recommendation Statement. JAMA J. Am. Med. Assoc. 2018, 319, 588-594. [CrossRef]

6. Schorge, J.O.; Clark, R.M.; Lee, S.I.; Penson, R.T. Primary Debulking Surgery for Advanced Ovarian Cancer: Are You a Believer or a Dissenter? Gynecol. Oncol. 2014, 135, 595-605. [CrossRef] [PubMed]

7. González-Martín, A.; Pothuri, B.; Vergote, I.; DePont Christensen, R.; Graybill, W.; Mirza, M.R.; McCormick, C.; Lorusso, D.; Hoskins, P.; Freyer, G.; et al. Niraparib in Patients with Newly Diagnosed Advanced Ovarian Cancer. N. Engl. J. Med. 2019, 381, 2391-2402. [CrossRef]

8. Mirza, M.R.; Monk, B.J.; Herrstedt, J.; Oza, A.M.; Mahner, S.; Redondo, A.; Fabbro, M.; Ledermann, J.A.; Lorusso, D.; Vergote, I.; et al. Niraparib Maintenance Therapy in Platinum-Sensitive, Recurrent Ovarian Cancer. N. Engl. J. Med. 2016, 375, 2154-2164. [CrossRef] [PubMed]

9. Cowan, R.A.; Chi, D.S. POINT: Primary Debulking Surgery vs. Neoadjuvant Chemotherapy for Newly Diagnosed Advanced Ovarian Cancer. Oncology (Williston Park. N.Y.) 2017, 31, 453.

10. Makar, A.P.; Tropé, C.G.; Tummers, P.; Denys, H.; Vandecasteele, K. Advanced Ovarian Cancer: Primary or Interval Debulking? Five Categories of Patients in View of the Results of Randomized Trials and Tumor Biology: Primary Debulking Surgery and Interval Debulking Surgery for Advanced Ovarian Cancer. Oncologist 2016, 21, 745-754. [CrossRef]

11. Elattar, A.; Bryant, A.; Winter-Roach, B.A.; Hatem, M.; Naik, R. Optimal Primary Surgical Treatment for Advanced Epithelial Ovarian Cancer. Cochrane Database Syst. Rev. 2011, 2011, CD007565. [CrossRef]

12. Chi, D.S.; Eisenhauer, E.L.; Lang, J.; Huh, J.; Haddad, L.; Abu-Rustum, N.R.; Sonoda, Y.; Levine, D.A.; Hensley, M.; Barakat, R.R. What Is the Optimal Goal of Primary Cytoreductive Surgery for Bulky Stage IIIC Epithelial Ovarian Carcinoma (EOC)? Gynecol. Oncol. 2006, 103, 559-564. [CrossRef]

13. Chang, S.J.; Bristow, R.E. Evolution of Surgical Treatment Paradigms for Advanced-Stage Ovarian Cancer: Redefining “optimal” Residual Disease. Gynecol. Oncol. 2012, 125, 483-492. [CrossRef]

14. Vergote, I.; Tropé, C.G.; Amant, F.; Kristensen, G.B.; Ehlen, T.; Johnson, N.; Verheijen, R.H.M.; van der Burg, M.E.L.; Lacave, A.J.; Panici, P.B.; et al. Neoadjuvant Chemotherapy or Primary Surgery in Stage IIIC or IV Ovarian Cancer. N. Engl. J. Med. 2010, 363, 943-953. [CrossRef] [PubMed]

15. Kehoe, S.; Hook, J.; Nankivell, M.; Jayson, G.C.; Kitchener, H.; Lopes, T.; Luesley, D.; Perren, T.; Bannoo, S.; Mascarenhas, M.; et al. Primary Chemotherapy versus Primary Surgery for Newly Diagnosed Advanced Ovarian Cancer (CHORUS): An Open-Label, Randomised, Controlled, Non-Inferiority Trial. Lancet 2015, 386, 249-257. [CrossRef]

16. Onda, T.; Satoh, T.; Saito, T.; Kasamatsu, T.; Nakanishi, T.; Nakamura, K.; Wakabayashi, M.; Takehara, K.; Saito, M.; Ushijima, K.; et al. Comparison of Treatment Invasiveness between Upfront Debulking Surgery versus Interval Debulking Surgery Following Neoadjuvant Chemotherapy for Stage III/IV Ovarian, Tubal, and Peritoneal Cancers in a Phase III Randomised Trial: Japan Clinical Oncology Group Study JCOG0602. Eur. J. Cancer 2016, 64, 22-31. [CrossRef] [PubMed]

17. Fagotti, A.; Ferrandina, G.; Vizzielli, G.; Fanfani, F.; Gallotta, V.; Chiantera, V.; Costantini, B.; Margariti, P.A.; Gueli Alletti, S.; Cosentino, F.; et al. Phase III Randomised Clinical Trial Comparing Primary Surgery versus Neoadjuvant Chemotherapy in Advanced Epithelial Ovarian Cancer with High Tumour Load (SCORPION Trial): Final Analysis of Peri-Operative Outcome. Eur. J. Cancer 2016, 59, 22-33. [CrossRef] [PubMed]

18. Dauplat, J.; Le Bouëdec, G.; Pomel, C.; Scherer, C. Cytoreductive Surgery for Advanced Stages of Ovarian Cancer. Semin. Surg. Oncol. 2000, 19, 42-48. [CrossRef]

19. Bristow, R.E.; Tomacruz, R.S.; Armstrong, D.K.; Trimble, E.L.; Montz, F.J. Survival Effect of Maximal Cytoreductive Surgery for Advanced Ovarian Carcinoma During the Platinum Era: A Meta-Analysis. J. Clin. Oncol. 2002, 20, 1248-1259. [CrossRef]

20. Gerestein, C.G.; Eijkemans, M.J.C.; De Jong, D.; Van Der Burg, M.E.L.; Dykgraaf, R.H.M.; Kooi, G.S.; Baalbergen, A.; Burger, C.W.; Ansink, A.C. The Prediction of Progression-Free and Overall Survival in Women with an Advanced Stage of Epithelial Ovarian Carcinoma. BJOG Int. J. Obstet. Gynaecol. 2009, 116, 372-380. [CrossRef]

21. Teramukai, S.; Ochiai, K.; Tada, H.; Fukushima, M. PIEPOC: A New Prognostic Index for Advanced Epithelial Ovarian Cancer-Japan Multinational Trial Organization OC01-01. J. Clin. Oncol. 2007, 25, 3302-3306. [CrossRef] 
22. Chi, D.S.; Palayekar, M.J.; Sonoda, Y.; Abu-Rustum, N.R.; Awtrey, C.S.; Huh, J.; Eisenhauer, E.L.; Barakat, R.R.; Kattan, M.W. Nomogram for Survival after Primary Surgery for Bulky Stage IIIC Ovarian Carcinoma. Gynecol. Oncol. 2008, 108, 191-194. [CrossRef]

23. Hendrickson, A.E.W.; Hawthorne, K.M.; Goode, E.L.; Kalli, K.R.; Goergen, K.M.; Bakkum-Gamez, J.N.; Cliby, W.A.; Keeney, G.L.; Visscher, D.W.; Tarabishy, Y.; et al. Assessment of Published Models and Prognostic Variables in Epithelial Ovarian Cancer at Mayo Clinic. Gynecol. Oncol. 2015, 137, 77-85. [CrossRef]

24. Mahdi, H.; Wiechert, A.; Lockhart, D.; Rose, P.G. Impact of Age on 30-Day Mortality and Morbidity in Patients Undergoing Surgery for Ovarian Cancer. Int. J. Gynecol. Cancer 2015, 25, 1216-1223. [CrossRef] [PubMed]

25. Langstraat, C.; Aletti, G.D.; Cliby, W.A. Morbidity, Mortality and Overall Survival in Elderly Women Undergoing Primary Surgical Debulking for Ovarian Cancer: A Delicate Balance Requiring Individualization. Gynecol. Oncol. 2011, 123, 187-191. [CrossRef] [PubMed]

26. Patankar, S.; Burke, W.M.; Hou, J.Y.; Tergas, A.I.; Huang, Y.; Ananth, C.V.; Neugut, A.I.; Hershman, D.L.; Wright, J.D. Risk Stratification and Outcomes of Women Undergoing Surgery for Ovarian Cancer. Gynecol. Oncol. 2015, 138, 62-69. [CrossRef] [PubMed]

27. Trillsch, F.; Woelber, L.; Eulenburg, C.; Braicu, I.; Lambrechts, S.; Chekerov, R.; Van Nieuwenhuysen, E.; Speiser, P.; Zeimet, A.; Castillo-Tong, D.C.; et al. Treatment Reality in Elderly Patients with Advanced Ovarian Cancer: A Prospective Analysis of the OVCAD Consortium. J. Ovarian Res. 2013, 6, 42. [CrossRef] [PubMed]

28. Digant, G.; Carolyn, A.L.; Pankaj, G.V.; Sadie, D.; James, F.G.; Christopher, G.L. Is Serum Albumin an Independent Predictor of Survival in Ovarian Cancer? Clin. Ovarian Cancer 2009, 2, 52-56. [CrossRef]

29. Kudsk, K.A.; Tolley, E.A.; DeWitt, R.C.; Janu, P.G.; Blackwell, A.P.; Yeary, S.; King, B.K. Preoperative Albumin and Surgical Site Identify Surgical Risk for Major Postoperative Complications. J. Parenter. Enter. Nutr. 2003, 27, 1-9. [CrossRef]

30. Nisar, P.J.; Appau, K.A.; Remzi, F.H.; Kiran, R.P. Preoperative Hypoalbuminemia Is Associated with Adverse Outcomes after Ileoanal Pouch Surgery. Inflamm. Bowel Dis. 2012, 18, 1034-1041. [CrossRef]

31. Ge, L.N.; Wang, F. Prognostic Significance of Preoperative Serum Albumin in Epithelial Ovarian Cancer Patients: A Systematic Review and Dose-Response Meta-Analysis of Observational Studies. Cancer Manag. Res. 2018, 10, 815-825. [CrossRef]

32. Weimann, A.; Braga, M.; Harsanyi, L.; Laviano, A.; Ljungqvist, O.; Soeters, P.; Jauch, K.W.; Kemen, M.; Hiesmayr, J.M.; Horbach, T.; et al. ESPEN Guidelines on Enteral Nutrition: Surgery Including Organ Transplantation. Clin. Nutr. 2006, 25, 224-244. [CrossRef]

33. Huhmann, M.B.; August, D.A. Review: Nutrition Support in Surgical Oncology. Nutr. Clin. Pract. 2009, 24, 520-526. [CrossRef]

34. Aletti, G.D.; Eisenhauer, E.L.; Santillan, A.; Axtell, A.; Aletti, G.; Holschneider, C.; Chi, D.S.; Bristow, R.E.; Cliby, W.A. Identification of Patient Groups at Highest Risk from Traditional Approach to Ovarian Cancer Treatment. Gynecol. Oncol. 2011, 120, 23-28. [CrossRef] [PubMed]

35. Joseph, N.; Clark, R.M.; Dizon, D.S.; Lee, M.S.; Goodman, A.; Boruta, D.; Schorge, J.O.; Del Carmen, M.G.; Growdon, W.B. Delay in Chemotherapy Administration Impacts Survival in Elderly Patients with Epithelial Ovarian Cancer. Gynecol. Oncol. 2015, 137, 401-405. [CrossRef] [PubMed]

36. Eisenkop, S.M.; Spirtos, N.M.; Friedman, R.L.; Lin, W.C.M.; Pisani, A.L.; Perticucci, S. Relative Influences of Tumor Volume before Surgery and the Cytoreductive Outcome on Survival for Patients with Advanced Ovarian Cancer: A Prospective Study. Gynecol. Oncol. 2003, 90, 390-396. [CrossRef]

37. ASA Physical Status Classification System | American Society of Anesthesiologists (ASA). Available online: https://www.asahq.org/standards-and-guidelines/asa-physical-status-classification-system (accessed on 18 May 2020).

38. Torres, D.; Kumar, A.; Bakkum-Gamez, J.N.; Weaver, A.L.; McGree, M.E.; Wang, C.; Langstraat, C.L.; Cliby, W.A. Mesenchymal Molecular Subtype Is an Independent Predictor of Severe Postoperative Complications after Primary Debulking Surgery for Advanced Ovarian Cancer. Gynecol. Oncol. 2019, 152, 223-227. [CrossRef] [PubMed]

39. Duffy, M.J. Tumor Markers in Clinical Practice: A Review Focusing on Common Solid Cancers. Med. Princ. Pract. 2013, 22, 4-11. [CrossRef] 
40. Nossov, V.; Amneus, M.; Su, F.; Lang, J.; Janco, J.M.T.; Reddy, S.T.; Farias-Eisner, R. The Early Detection of Ovarian Cancer: From Traditional Methods to Proteomics. Can We Really Do Better than Serum CA-125? Am. J. Obstet. Gynecol. 2008, 199, 215-223. [CrossRef]

41. Kobayashi, E.; Ueda, Y.; Matsuzaki, S.; Yokoyama, T.; Kimura, T.; Yoshino, K.; Fujita, M.; Kimura, T.; Enomoto, T. Biomarkers for Screening, Diagnosis, and Monitoring of Ovarian Cancer. Cancer Epidemiol. Biomark. Prev. 2012, 21, 1902-1912. [CrossRef]

42. Duffy, M.J.; Bonfrer, J.M.; Kulpa, J.; Rustin, G.J.S.; Soletormos, G.; Torre, G.C.; Tuxen, M.K.; Zwirner, M. CA125 in Ovarian Cancer: European Group on Tumor Markers Guidelines for Clinical Use. Int. J. Gynecol. Cancer 2005, 15, 679-691. [CrossRef]

43. Gohagan, J.K.; Prorok, P.C.; Hayes, R.B.; Kramer, B.S. The Prostate, Lung, Colorectal and Ovarian (PLCO) Cancer Screening Trial of the National Cancer Institute: History, Organization, and Status. Control. Clin. Trials 2000, 21, 251S-272S. [CrossRef]

44. Menon, U.; Gentry-Maharaj, A.; Hallett, R.; Ryan, A.; Burnell, M.; Sharma, A.; Lewis, S.; Davies, S.; Philpott, S.; Lopes, A.; et al. Sensitivity and Specificity of Multimodal and Ultrasound Screening for Ovarian Cancer, and Stage Distribution of Detected Cancers: Results of the Prevalence Screen of the UK Collaborative Trial of Ovarian Cancer Screening (UKCTOCS). Lancet Oncol. 2009, 10, 327-340. [CrossRef]

45. Buys, S.S.; Partridge, E.; Black, A.; Johnson, C.C.; Lamerato, L.; Isaacs, C.; Reding, D.J.; Greenlee, R.T.; Yokochi, L.A.; Kessel, B.; et al. Effect of Screening on Ovarian Cancer Mortality: The Prostate, Lung, Colorectal and Ovarian (PLCO) Cancer Screening Randomized Controlled Trial. JAMA J. Am. Med. Assoc. 2011, 305, 2295-2302. [CrossRef] [PubMed]

46. Menon, U.; McGuire, A.J.; Raikou, M.; Ryan, A.; Davies, S.K.; Burnell, M.; Gentry-Maharaj, A.; Kalsi, J.K.; Singh, N.; Amso, N.N.; et al. The Cost-Effectiveness of Screening for Ovarian Cancer: Results from the UK Collaborative Trial of Ovarian Cancer Screening (UKCTOCS). Br. J. Cancer 2017, 117, 619-627. [CrossRef] [PubMed]

47. The Role of the Obstetrician-Gynecologist in the Early Detection of Epithelial Ovarian Cancer in Women at Average Risk | ACOG. Available online: https:/www.acog.org/clinical/clinical-guidance/committee-opinion/ articles/2017/09/the-role-of-the-obstetriciangynecologist-in-the-early-detection-of-epithelial-ovarian-can cer-in-women-at-average-risk (accessed on 8 April 2020).

48. Henderson, J.T.; Webber, E.M.; Sawaya, G.F. Screening for Ovarian Cancer Updated Evidence Report and Systematic Review for the US Preventive Services Task Force. JAMA J. Am. Med. Assoc. 2018, 319, 595-606. [CrossRef] [PubMed]

49. Helzlsouer, K.J.; Bush, T.L.; Alberg, A.J.; Bass, K.M.; Zacur, H.; Comstock, G.W. Prospective Study of Serum CA-125 Levels as Markers of Ovarian Cancer. JAMA 1993, 269, 1123-1126. [CrossRef]

50. Chi, D.S.; Venkatraman, E.S.; Masson, V.; Hoskins, W.J. The Ability of Preoperative Serum CA-125 to Predict Optimal Primary Tumor Cytoreduction in Stage III Epithelial Ovarian Carcinoma. Gynecol. Oncol. 2000, 77, 227-231. [CrossRef]

51. Gemer, O.; Segal, S.; Kopmar, A. Preoperative CA-125 Level as a Predictor of Non Optimal Cytoreduction of Advanced Epithelial Ovarian Cancer. Acta Obstet. Gynecol. Scand. 2001, 80, 583-585. [CrossRef]

52. Huhtinen, K.; Suvitie, P.; Hiissa, J.; Junnila, J.; Huvila, J.; Kujari, H.; Setälä, M.; Härkki, P.; Jalkanen, J.; Fraser, J.; et al. Serum HE4 Concentration Differentiates Malignant Ovarian Tumours from Ovarian Endometriotic Cysts. Br. J. Cancer 2009, 100, 1315-1319. [CrossRef]

53. Vallius, T.; Hynninen, J.; Auranen, A.; Matomäki, J.; Oksa, S.; Roering, P.; Grènman, S. Postoperative Human Epididymis Protein 4 Predicts Primary Therapy Outcome in Advanced Epithelial Ovarian Cancer. Tumor Biol. 2017, 39, 1-8. [CrossRef]

54. Yang, Z.; Luo, Z.; Zhao, B.; Zhang, W.; Zhang, J.; Li, Z.; Li, L. Diagnosis and Preoperative Predictive Value of Serum HE4 Concentrations for Optimal Debulking in Epithelial Ovarian Cancer. Oncol. Lett. 2013, 6, $28-34$. [CrossRef]

55. Feng, L.Y.; Liao, S.B.; Li, L. Preoperative Serum Levels of HE4 and CA125 Predict Primary Optimal Cytoreduction in Advanced Epithelial Ovarian Cancer: A Preliminary Model Study. J. Ovarian Res. 2020, $13,17$. [CrossRef] 
56. Chudecka-Głaz, A.; Cymbaluk-Płoska, A.; Wȩaowska, M.; Menkiszak, J. Could HE4 Level Measurements during Firstline Chemotherapy Predict Response to Treatment among Ovarian Cancer Patients? PLoS ONE 2018, 13, e0194270. [CrossRef] [PubMed]

57. Valentin, L.; Hagen, B.; Tingulstad, S.; Eik-Nes, S. Comparison of "pattern Recognition" and Logistic Regression Models for Discrimination between Benign and Malignant Pelvic Masses: A Prospective Cross Validation. Ultrasound Obstet. Gynecol. 2001, 18, 357-365. [CrossRef] [PubMed]

58. Smorgick, N.; Maymon, R. Assessment of Adnexal Masses Using Ultrasound: A Practical Review. Int. J. Womens Health 2014, 6, 857-863. [CrossRef] [PubMed]

59. De Blasis, I.; Moruzzi, M.C.; Moro, F.; Mascilini, F.; Cianci, S.; Gueli Alletti, S.; Turco, L.C.; Garganese, G.; Scambia, G.; Testa, A.C. Role of Ultrasound in Advanced Peritoneal Malignancies. Minerva Med. 2019, 110, 292-300. [CrossRef]

60. Schorge, J.O.; Bradfrd, L.S.; del Camen, M.G. Primary Cytoreductive Surgery for Advanced Ovarian Cancer: Is It the Past, Present, or Future? Clin. Adv. Hematol. Oncol. 2011, 9, 912-918.

61. Chacón, E.; Alcázar, J.; Mínguez, J.; Carriles, I.; Manzour, N.; Vázquez, D.; Castellanos, T.; González-Martín, A.; Sánchez, L.; Espinós, J.; et al. EP815 | Ultrasound-Based Score for Predicting Debulking Surgery Outcome in IIB-IV Stage Epithelial Ovarian Cancer. ePoster 2019, 29, A450-A451. [CrossRef]

62. Salani, R.; Backes, F.J.; Fung Kee Fung, M.; Holschneider, C.H.; Parker, L.P.; Bristow, R.E.; Goff, B.A. Posttreatment Surveillance and Diagnosis of Recurrence in Women with Gynecologic Malignancies: Society of Gynecologic Oncologists Recommendations. Am. J. Obstet. Gynecol. 2011, 204, 466-478. [CrossRef]

63. Morgan, R.J.; Alvarez, R.D.; Armstrong, D.K.; Burger, R.A.; Chen, L.M.; Copeland, L.; Crispens, M.A.; Gershenson, D.M.; Gray, H.J.; Hakam, A.; et al. Ovarian Cancer, Version 2.2013: Featured Updates to the NCCN Guidelines. JNCCN J. Natl. Compr. Cancer Netw. 2013, 11, 1199-1209. [CrossRef]

64. SGO-ROUTINE Imaging for Cancer Surveillance / Choosing Wisely. Available online: https://www.choosing wisely.org/clinician-lists/society-gynecologic-oncology-routine-imaging-for-surveillance-gynecologic-cancer/ (accessed on 9 April 2020).

65. Esselen, K.M.; Cronin, A.M.; Bixel, K.; Bookman, M.A.; Burger, R.A.; Cohn, D.E.; Cristea, M.; Griggs, J.J.; Levenback, C.F.; Mantia-Smaldone, G.; et al. Use of CA-125 Tests and Computed Tomographic Scans for Surveillance in Ovarian Cancer. JAMA Oncol. 2016, 2, 1427-1433. [CrossRef]

66. Dowdy, S.C.; Mullany, S.A.; Brandt, K.R.; Huppert, B.J.; Cliby, W.A. The Utility of Computed Tomography Scans in Predicting Suboptimal Cytoreductive Surgery in Women with Advanced Ovarian Carcinoma. Cancer 2004, 101, 346-352. [CrossRef]

67. Borley, J.; Wilhelm-Benartzi, C.; Yazbek, J.; Williamson, R.; Bharwani, N.; Stewart, V.; Carson, I.; Hird, E.; McIndoe, A.; Farthing, A.; et al. Radiological Predictors of Cytoreductive Outcomes in Patients with Advanced Ovarian Cancer. BJOG Int. J. Obstet. Gynaecol. 2015, 122, 843-849. [CrossRef] [PubMed]

68. Nelson, B.E.; Rosenfield, A.T.; Schwartz, P.E. Preoperative Abdominopelvic Computed Tomographic Prediction of Optimal Cytoreduction in Epithelial Ovarian Carcinoma. J. Clin. Oncol. 1993, 11, 166-172. [CrossRef] [PubMed]

69. Everett, E.N.; Heuser, C.C.; Pastore, L.M.; Anderson, W.A.; Rice, L.W.; Irvin, W.P.; Taylor, P.T.; Burrell, M. Predictors of Suboptimal Surgical Cytoreduction in Women Treated with Initial Cytoreductive Surgery for Advanced Stage Epithelial Ovarian Cancer. Am. J. Obstet. Gynecol. 2005, 193, 568-574. [CrossRef] [PubMed]

70. Axtell, A.E.; Lee, M.H.; Bristow, R.E.; Dowdy, S.C.; Cliby, W.A.; Raman, S.; Weaver, J.P.; Gabbay, M.; Ngo, M.; Lentz, S.; et al. Multi-Institutional Reciprocal Validation Study of Computed Tomography Predictors of Suboptimal Primary Cytoreduction in Patients with Advanced Ovarian Cancer. J. Clin. Oncol. 2007, 25, 384-389. [CrossRef]

71. Mackintosh, M.L.; Rahim, R.; Rajashanker, B.; Swindell, R.; Kirmani, B.H.; Hunt, J.; Brockbank, E.; Barton, D.P.J.; Clayton, R.D. CT Scan Does Not Predict Optimal Debulking in Stage III-IV Epithelial Ovarian Cancer: A Multicentre Validation Study. J. Obstet. Gynaecol. (Lahore) 2014, 34, 424-428. [CrossRef]

72. Hu, T.W.Y.; Nie, D.; Gou, J.H.; Li, Z.Y. Predictive Significance of Preoperative CT Findings for Suboptimal Cytoreduction in Advanced Ovarian Cancer: A Meta-Analysis. Cancer Manag. Res. 2018, 10, 2019-2030. [CrossRef] 
73. Bristow, R.E.; Duska, L.R.; Lambrou, N.C.; Fishman, E.K.; O’Neill, M.J.; Trimble, E.L.; Montz, F.J. A Model for Predicting Surgical Outcome in Patients with Advanced Ovarian Carcinoma Using Computed Tomography. Cancer 2000, 89, 1532-1540. [CrossRef]

74. Gerestein, C.G.; Eijkemans, M.J.; Bakker, J.; Elgersma, O.E.; Van Der Burg, M.E.L.; Kooi, G.S.; Burger, C.W. Nomogram for Suboptimal Cytoreduction at Primary Surgery for Advanced Sage Ovarian Cancer. Anticancer Res. 2011, 31, 4043-4049.

75. Janco, J.M.T.; Glaser, G.; Kim, B.; McGree, M.E.; Weaver, A.L.; Cliby, W.A.; Dowdy, S.C.; Bakkum-Gamez, J.N. Development of a Prediction Model for Residual Disease in Newly Diagnosed Advanced Ovarian Cancer. Gynecol. Oncol. 2015, 138, 70-77. [CrossRef]

76. Engbersen, M.P.; van't Sant, I.; Lok, C.; Lambregts, D.M.J.; Sonke, G.S.; Beets-Tan, R.G.H.; van Driel, W.J.; Lahaye, M.J. MRI with Diffusion-Weighted Imaging to Predict Feasibility of Complete Cytoreduction with the Peritoneal Cancer Index (PCI) in Advanced Stage Ovarian Cancer Patients. Eur. J. Radiol. 2019, 114, 146-151. [CrossRef]

77. Garcia Prado, J.; González Hernando, C.; Varillas Delgado, D.; Saiz Martínez, R.; Bhosale, P.; Blazquez Sanchez, J.; Chiva, L. Diffusion-Weighted Magnetic Resonance Imaging in Peritoneal Carcinomatosis from Suspected Ovarian Cancer: Diagnostic Performance in Correlation with Surgical Findings. Eur. J. Radiol. 2019, 121, 108696. [CrossRef] [PubMed]

78. Nezhat, F.R.; Pejovic, T.; Finger, T.N.; Khalil, S.S. Role of Minimally Invasive Surgery in Ovarian Cancer. J. Minim. Invasive Gynecol. 2013, 20, 754-765. [CrossRef] [PubMed]

79. Liang, H.; Guo, H.; Zhang, C.; Zhu, F.L.; Wu, Y.; Zhang, K.; Li, H.; Han, J. Feasibility and Outcome of Primary Laparoscopic Cytoreductive Surgery for Advanced Epithelial Ovarian Cancer: A Comparison to Laparotomic Surgery in Retrospective Cohorts. Oncotarget 2017, 8, 113239-113247. [CrossRef] [PubMed]

80. Fanning, J.; Hojat, R.; Johnson, J.; Fenton, B. Laparoscopic Cytoreduction for Primary Advanced Ovarian Cancer. J. Soc. Laparoendosc. Surg. 2010, 14, 80-82. [CrossRef]

81. Abitbol, J.; Gotlieb, W.; Zeng, Z.; Ramanakumar, A.; Kessous, R.; Kogan, L.; Pare-Miron, V.; Rombaldi, M.; Salvador, S.; Kucukyazici, B.; et al. Incorporating Robotic Surgery into the Management of Ovarian Cancer after Neoadjuvant Chemotherapy. Int. J. Gynecol. Cancer 2019, 29, 1341-1350. [CrossRef]

82. Melamed, A.; Rauh-Hain, J.A. Minimally Invasive Interval Cytoreductive Surgery: It's Time for a Randomized Trial. Int. J. Gynecol. Cancer 2019, 29, 1339-1340. [CrossRef]

83. Fagotti, A.; Fanfani, F.; Ludovisi, M.; Voi, R.L.; Bifulco, G.; Testa, A.C.; Scambia, G. Role of Laparoscopy to Assess the Chance of Optimal Cytoreductive Surgery in Advanced Ovarian Cancer: A Pilot Study. Gynecol. Oncol. 2005, 96, 729-735. [CrossRef]

84. Chereau, E.; Lavoue, V.; Ballester, M.; Coutant, C.; Selle, F.; Cortez, A.; Daraï, E.; Leveque, J.; Rouzier, R. External Validation of a Laparoscopic-Based Score to Evaluate Resectability for Patients with Advanced Ovarian Cancer Undergoing Interval Debulking Surgery. Anticancer Res. 2011, 31, 4469-4474.

85. Tomar, T.; Nair, R.; Sambasivan, S.; Krishna, K.J.; Mathew, A.; Iqbal Ahmed, M. Role of Laparoscopy in Predicting Surgical Outcomes in Patients Undergoing Interval Cytoreduction Surgery for Advanced Ovarian Carcinoma: A Prospective Validation Study. Indian J. Cancer 2017, 54, 550. [CrossRef]

86. Shivkumaran, S.; Mandakulutur, G.; Banavara, K. Role of Staging Laparoscopy to Evaluate Feasibility of Performing Optimal Cytoreductive Surgery in Epithelial Ovarian Cancers. Int. J. Res. Med. Sci. 2016, 4, 5099-5102. [CrossRef]

87. Laparoscopy in Diagnosing Extensiveness of Ovarian Cancer | Cochrane. Available online: https://www. cochrane.org/CD009786/GYNAECA_laparoscopy-diagnosing-extensiveness-ovarian-cancer (accessed on 9 April 2020).

88. Rutten, M.J.; Van Meurs, H.S.; Van De Vrie, R.; Naaktgeboren, C.A.; Fons, G.; Opmeer, B.C.; Spijkerboer, A.; Bossuyt, P.M.M.; Kenter, G.G.; Buist, M.R.; et al. Laparoscopy to Predict the Result of Primary Cytoreductive Surgery in Patients with Advanced Ovarian Cancer: A Randomized Controlled Trial. J. Clin. Oncol. 2017, 35, 613-621. [CrossRef] [PubMed]

89. Kim, M.; Suh, D.H.; Choi, J.Y.; Bu, J.; Kang, Y.-T.; Kim, K.; No, J.H.; Kim, Y.B.; Cho, Y.-H. Post-Debulking Circulating Tumor Cell as a Poor Prognostic Marker in Advanced Stage Ovarian Cancer. Medicine (Baltimore) 2019, 98, e15354. [CrossRef] [PubMed] 
90. Pantel, K.; Alix-Panabières, C. Liquid Biopsy and Minimal Residual Disease-Latest Advances and Implications for Cure. Nat. Rev. Clin. Oncol. 2019, 16, 409-424. [CrossRef] [PubMed]

91. Guo, Y.X.; Neoh, K.H.; Chang, X.H.; Sun, Y.; Cheng, H.Y.; Ye, X.; Ma, R.Q.; Han, R.P.S.; Cui, H. Diagnostic Value of HE4+ Circulating Tumor Cells in Patients with Suspicious Ovarian Cancer. Oncotarget 2018, 9, 7522-7533. [CrossRef]

92. Obermayr, E.; Maritschnegg, E.; Agreiter, C.; Pecha, N.; Speiser, P.; Helmy-Bader, S.; Danzinger, S.; Krainer, M.; Singer, C.; Zeillinger, R. Efficient Leukocyte Depletion by a Novel Microfluidic Platform Enables the Molecular Detection and Characterization of Circulating Tumor Cells. Oncotarget 2018, 9, 812-823. [CrossRef]

93. Kolostova, K.; Pinkas, M.; Jakabova, A.; Pospisilova, E.; Svobodova, P.; Spicka, J.; Cegan, M.; Matkowski, R.; Bobek, V. Molecular Characterization of Circulating Tumor Cells in Ovarian Cancer. Am. J. Cancer Res. 2016, $6,973-980$.

94. Obermayr, E.; Agreiter, C.; Schuster, E.; Fabikan, H.; Weinlinger, C.; Baluchova, K.; Hamilton, G.; Hochmair, M.; Zeillinger, R. Molecular Characterization of Circulating Tumor Cells Enriched by A Microfluidic Platform in Patients with Small-Cell Lung Cancer. Cells 2019, 8, 880. [CrossRef]

95. Pereira, E.; Camacho-Vanegas, O.; Anand, S.; Sebra, R.; Catalina Camacho, S.; Garnar-Wortzel, L.; Nair, N.; Moshier, E.; Wooten, M.; Uzilov, A.; et al. Personalized Circulating Tumor DNA Biomarkers Dynamically Predict Treatment Response and Survival In Gynecologic Cancers. PLoS ONE 2015, 10, e0145754. [CrossRef]

96. Arend, R.C.; Londoño, A.I.; Montgomery, A.M.; Smith, H.J.; Dobbin, Z.C.; Katre, A.A.; Martinez, A.; Yang, E.S.; Alvarez, R.D.; Huh, W.K.; et al. Molecular Response to Neoadjuvant Chemotherapy in High-Grade Serous Ovarian Carcinoma. Mol. Cancer Res. 2018, 16, 813-824. [CrossRef]

97. Nakamura, K.; Sawada, K.; Kobayashi, M.; Miyamoto, M.; Shimizu, A.; Yamamoto, M.; Kinose, Y.; Kimura, T. Role of the Exosome in Ovarian Cancer Progression and Its Potential as a Therapeutic Target. Cancers 2019, 11, 1147. [CrossRef]

98. Yang, J.; Li, G.; Zhang, K. MiR-125a Regulates Ovarian Cancer Proliferation and Invasion by Repressing GALNT14 Expression. Biomed. Pharm. 2016, 80, 381-387. [CrossRef] [PubMed]

99. Zuberi, M.; Khan, I.; Mir, R.; Gandhi, G.; Ray, P.C.; Saxena, A. Utility of Serum MiR-125b as a Diagnostic and Prognostic Indicator and Its Alliance with a Panel of Tumor Suppressor Genes in Epithelial Ovarian Cancer. PLoS ONE 2016, 11. [CrossRef] [PubMed]

100. Becker, A.; Thakur, B.K.; Weiss, J.M.; Kim, H.S.; Peinado, H.; Lyden, D. Extracellular Vesicles in Cancer: Cell-to-Cell Mediators of Metastasis. Cancer Cell 2016, 30, 836-848. [CrossRef] [PubMed]

101. Johnston, C.; Ng, J.S.; Manchanda, R.; Tsunoda, A.T.; Chuang, L. Variations in Gynecologic Oncology Training in Low (LIC) and Middle Income (MIC) Countries (LMICs): Common Efforts and Challenges. Gynecol. Oncol. Rep. 2017, 20, 9-14. [CrossRef] [PubMed]

102. Dahm-Kähler, P.; Palmqvist, C.; Staf, C.; Holmberg, E.; Johannesson, L. Centralized Primary Care of Advanced Ovarian Cancer Improves Complete Cytoreduction and Survival-A Population-Based Cohort Study. Gynecol. Oncol. 2016, 142, 211-216. [CrossRef]

103. Are, C.; Caniglia, A.; Malik, M.; Cummings, C.; Lecoq, C.; Berman, R.; Audisio, R.; Wyld, L. Variations in Training of Surgical Oncologists: Proposal for a Global Curriculum. Eur. J. Surg. Oncol. 2016, 42, 767-778. [CrossRef]

104. Sullivan, R.; Alatise, O.I.; Anderson, B.O.; Audisio, R.; Autier, P.; Aggarwal, A.; Balch, C.; Brennan, M.F.; Dare, A.; D'Cruz, A.; et al. Global Cancer Surgery: Delivering Safe, Affordable, and Timely Cancer Surgery. Lancet Oncol. 2015, 16, 1193-1224. [CrossRef]

105. Sterling, L.; van Lonkhuijzen, L.; Nyangena, J.; Orango, E.; Strother, M.; Busakhala, N.; Rosen, B. Protocol Development for Ovarian Cancer Treatment in Kenya: A Brief Report. Int. J. Gynecol. Cancer 2011, 21, $424-427$. [CrossRef]

106. Tran, A.Q.; Erim, D.O.; Sullivan, S.A.; Cole, A.L.; Barber, E.L.; Kim, K.H.; Gehrig, P.A.; Wheeler, S.B. Cost Effectiveness of Neoadjuvant Chemotherapy Followed by Interval Cytoreductive Surgery versus Primary Cytoreductive Surgery for Patients with Advanced Stage Ovarian Cancer during the Initial Treatment Phase. Gynecol. Oncol. 2018, 148, 329-335. [CrossRef]

107. Poonawalla, I.B.; Lairson, D.R.; Chan, W.; Piller, L.B.; Du, X.L. Cost-Effectiveness of Neoadjuvant Chemotherapy versus Primary Surgery in Elderly Patients with Advanced Ovarian Cancer. Value Health 2015, 18, 387-395. [CrossRef] 
108. Forde, G.K.; Chang, J.; Ziogas, A. Cost-Effectiveness of Primary Debulking Surgery When Compared to Neoadjuvant Chemotherapy in the Management of Stage IIIC and IV Epithelial Ovarian Cancer. Clin. Outcomes Res. 2016, 8, 397-406. [CrossRef] [PubMed]

109. Vergote, I.; Coens, C.; Nankivell, M.; Kristensen, G.B.; Parmar, M.K.B.; Ehlen, T.; Jayson, G.C.; Johnson, N.; Swart, A.M.; Verheijen, R.; et al. Neoadjuvant Chemotherapy versus Debulking Surgery in Advanced TuboOvarian Cancers: Pooled Analysis of Individual Patient Data from the EORTC 55971 and CHORUS Trials. Lancet Oncol. 2018, 19, 1680-1687. [CrossRef]

(C) 2020 by the authors. Licensee MDPI, Basel, Switzerland. This article is an open access article distributed under the terms and conditions of the Creative Commons Attribution (CC BY) license (http://creativecommons.org/licenses/by/4.0/). 